\title{
Pathophysiology and epidemiology of virus-induced asthma
}

\author{
Hirokazu Kimura ${ }^{1 *}$ and Akihide Ryo ${ }^{2 *}$ \\ ${ }^{1}$ Infectious Disease Surveillance Center, National Institute of Infectious Diseases, Tokyo, Japan \\ 2 Department of Molecular Biodefence Research, Yokohama City University Graduate School of Medicine, Kanagawa, Japan \\ *Correspondence: kimhiro@nih.go.jp; aryo@yokohama-cu.ac.jp
}

Edited and reviewed by:

Akio Adachi, The University of Tokushima Graduate School, Japan

Keywords: virus-induced asthma, epidemiology, pathology, respiratory virus, human immunity

Many respiratory viruses are mainly responsible for common cold, bronchitis, bronchiolitis, and pneumonia. Furthermore, asthma and chronic obstructive pulmonary disease (COPD) are major cause of mortality. The prevalence of asthma in developed countries is approximately $10 \%$ in adults and even higher in children (Barnes, 2008). Thus, the medical costs for these diseases are a major burden in many countries. Respiratory virus infections also cause the most of acute exacerbation of asthma (virusinduced asthma) or COPD. Among them, human rhinoviruses (HRV) are detected in the two thirds of the cases with asthma exacerbations in children (Johnston et al., 1995). However, epidemiology and pathophysiology of asthma and COPD is not known. Furthermore, a few effective vaccines have been applied. Therefore, it may be important to better understand pathophysiology of virus-induced asthma or virus-induced COPD exacerbation. Both aspects of the virus agents and host defense systems including acute/chronic inflammation and airway tissue remodeling should be clarified. This e-book aims to review and discuss pathophysiology and epidemiology of virus-induced asthma and COPD focusing on new findings of the host immunity and virology.

This Research Topic contains 7 review articles and 3 original articles regarding pathophysiology of virus-induced asthma. As the first article, Kudo et al. (2013) reviewed pathology of asthma. This article globally covers from molecular histopathology involved in cytokine networks of asthma. The readers may easily understand molecular immunopathology of virus-induced asthma. In the second issue, Okayama (2013) presents cellular and humoral immunity of asthma. Accumulating evidence implicates that the genetic and environmental factors may be associated with virus-induced asthma. This work focuses on the immunological mechanisms that may explain why asthma is associated with RSV-and HRV-infection. As the third review article, Kimura et al. (2013) present the molecular mechanisms between various cytokines and innate immunity of viral respiratory infections including virus-induced asthma. The authors also show the signaling pathways with regard to them. In the 4th review article, Tsukagoshi et al. (2013) discuss the genetic characteristics and molecular evolution of respiratory viruses, and epidemiology of asthma. They also show phylogenetic analysis of the detected viruses in the children with respiratory syncytial virus- (RSV) and/or HRV-associated wheezing and asthma.
As the 5th review article, Inoue and Shimojo (2013) present epidemiology and pathophysiology of virus-induced asthma in children. They summarize the previous findings and discuss how clinicians can effectively intervene in these viral infections to prevent the development of asthma. Next, Kurai et al. (2013) and Saraya et al. (2014) present pathophysiology of virus-induced COPD and asthma in adults. They summarize current knowledge concerning exacerbation of both COPD and asthma by focusing on the clinical significance of associated respiratory virus infections. Furthermore, influenza $\mathrm{A}(\mathrm{H} 1 \mathrm{~N} 1) \mathrm{pdm} 09$ virus have suddenly emerged in Mexico in the spring, 2009. The virus can cause influenza pandemy accompanying with pneumonia/wheezing. Obuchi et al. (2013) review essential reports with regard to asthma in patients infected with the virus, and they discuss the utility of influenza vaccines and antivirals. Although HPIV3 is an etiological agent for respiratory disorders such as pneumonia and asthma, there is no prophylactic human vaccine against the virus infection. In the 9th issue as original article, Senchi et al. (2013) present the development of an oligomannosecoated liposome (OML) nasal vaccine against HPIV3 in combination with an effective adjuvant Poly(I:C). They report that their newly-developed vaccine can successfully induce antigen-specific immunity with a small amount of antigen via the nasal route. These results highlight the utility of combining sophisticated systems in the development of a novel vaccine against HPIV3. In the final article, Matsunaga et al. (2014) present the development of monoclonal antibodies (MAbs) against hemagglutininneuraminidase (HN) of HPIV3. For synthesizing the antigen protein, they utilized the wheat germ cell-free system. This new cell-free system-based protocol for antigen production enabled to create the MAbs that can be applicable in various immune assays such as flowcytometry and immunoprecipitation analyses. The newly-developed MAbs could thus be a valuable tool for the study of HPIV3 infection as well as the several diagnostic tests of this virus.

In conclusion, we believe that these works are well summarized and informative to glimpse the field of virus-associated asthma/COPD, and may help understanding the basic and clinical aspects of the disease. We would be happy if this collection of papers will offer new stimuli and perspectives for not only researchers but also clinicians working around the exciting and emerging the e-book. 


\section{REFERENCES}

Barnes, P. J. (2008). Immunology of asthma and chronic obstructive pulmonary disease. Nat. Rev. Immunol. 8, 183-192. doi: 10.1038/nri2254

Inoue, Y., and Shimojo, N. (2013). Epidemiology of virus-induced wheezing/asthma in children. Front. Microbiol. 4:391. doi: 10.3389/fmicb.2013. 00391

Johnston, S. L., Pattemore, P. K., Sanderson, G., Smith, S., Lampe, F., Josephs, L., et al. (1995). Community study of role of viral infections in exacerbations of asthma in 9-11 year old children. BMJ 310, 1225-1229.

Kimura, H., Yoshizumi, M., Ishii, H., Oishi, K., and Ryo, A. (2013). Cytokine production and signaling pathways in respiratory virus infection. Front. Microbiol. 4:276. doi: 10.3389/fmicb.2013.00276

Kudo, M., Ishigatsubo, Y., and Aoki, I. (2013). Pathology of asthma. Front. Microbiol. 4:263. doi: 10.3389/fmicb.2013.00263

Kurai, D., Saraya, T., Ishii, H., and Takizawa, H. (2013). Virus-induced exacerbations in asthma and COPD. Front. Microbiol. 4:293. doi: 10.3389/fmicb.2013.00293

Matsunaga, S., Kawakami, S., Matsuo, I., Okayama, A., Tsukagoshi, H., Kudoh, A., et al. (2014). Wheat germ cell-free system-based production of hemagglutininneuraminidase glycoprotein of human parainfluenza virus type 3 for generation and characterization of monoclonal antibody. Front. Microbiol. 5:208. doi: 10.3389/fmicb.2014.00208

Obuchi, M., Adachi, Y., Takizawa, T., and Sata, T. (2013). Influenza A(H1N1)pdm09 virus and asthma. Front. Microbiol. 4:307. doi: 10.3389/fmicb.2013.00307

Okayama, Y. (2013). Cellular and humoral immunity of virus-induced asthma. Front. Microbiol. 4:252. doi: 10.3389/fmicb.2013.00252
Saraya, T., Kurai, D., Ishii, H., Ito, A., Sasaki, Y., Niwa, S., et al. (2014). Epidemiology of virus-induced asthma exacerbations: with special reference to the role of human rhinovirus. Front. Microbiol. 5:226. doi: 10.3389/fmicb.2014.00226

Senchi, K., Matsunaga, S., Hasegawa, H., Kimura, H., and Ryo, A. (2013). Development of oligomannose-coated liposome-based nasal vaccine against human parainfluenza virus type 3. Front. Microbiol. 4:346. doi: $10.3389 /$ fmicb. 2013.00346

Tsukagoshi, H., Ishioka, T., Noda, M., Kozawa, K., and Kimura, H. (2013). Molecular epidemiology of respiratory viruses in virus-induced asthma. Front. Microbiol. 4:278. doi: 10.3389/fmicb.2013.00278

Conflict of Interest Statement: The authors declare that the research was conducted in the absence of any commercial or financial relationships that could be construed as a potential conflict of interest.

Received: 02 October 2014; accepted: 07 October 2014; published online: 22 October 2014.

Citation: Kimura H and Ryo A (2014) Pathophysiology and epidemiology of virusinduced asthma. Front. Microbiol. 5:562. doi: 10.3389/fmicb.2014.00562

This article was submitted to Virology, a section of the journal Frontiers in Microbiology.

Copyright (C) 2014 Kimura and Ryo. This is an open-access article distributed under the terms of the Creative Commons Attribution License (CC BY). The use, distribution or reproduction in other forums is permitted, provided the original author(s) or licensor are credited and that the original publication in this journal is cited, in accordance with accepted academic practice. No use, distribution or reproduction is permitted which does not comply with these terms. 